ment thateoerer. The emaciation continued to progress; mi for the last two months was particularly rapid, diarrhoea being often a concomitant. It must aloo be added, that pain wes occasionally present in the right renal region.

Present State. When examined by Dr. Speer and myself, sbout a fortnight before his death, there was extreme emaciation; the skin had that white waxy appearance, slightly tinged with yellow, so characteristic of the cancerous cachexy, of which, indeed, the entire symptoms were fully dereloped. Tho stomach had lost its power, as evidenced by the continuance of romiting, nausea, and the other allied symptoms mentioned in the previous history. The urine, hich was seen at this examination, contained a number of fiat, oral, almost colourless coagula. The pulse was exceedingly small and weak, and the radial artery on the left side could not be felt at all. On the left side of the abdomen was a tumour occupying nearly the whole side of that cavity, extending from the renal region and pressing forwards on the anterior wall of the abdomen, this tumour was moreable, and by pressing it forwards from the proper situation of the kidney, the whole substance moved and raised the abdominal parietes anteriorly. This proved that the tumour was cither in relation with the kidney, or was the kidney itself enormously enlarged. This fact, together with the frequent attacks of hrmaturia, and the well marked development of the cancerous cachexy, led us to form the opinion that the disease was cancer of the kidney. I am quite aware, from the post mortem examination, that the right kidney also might have had a share in producing the hæmaturia. The patient died about a fortnight after my first visit; the marasmus rapidly increasing, until he sank completely exhausted.

Exannination of the body, made by Dr. Speer. Emaciation was extreme. The tumour was apparent externally, occupying the lumbar region, and filling the whole space between the left hypochondrium and iliac region, and extending to the mesial line. Upon opening the body, the tumour was found covered by omentum, not adherent; then by a peritoneal coating : it adhered to the small intestines in its vicinity, and was everywhere bound down behind by peritoneum. It was removed partly by dissection and partly by tearing it away from its connexions. It was then found that there was no kidney behind it. The spleen appeared above it. The tumour, in fact, was the kidney, greatly enlarged, and changed into a mass of encephaloid cancer. It measured in length about seven inches and a half, in width fire inches, in thickness about four inches. Its weight was between three and four pounds, by conjecture; no means of accurately ascertaining this point being at hand.

Upon cutting the tumour open longitudinally, some remains of the structure of the kidney were slightly apparent; such as the distinction between the cortical and medullary parts. Very little of its anatomical structure, however, could be recognised. The pelvis of the right kidney was filled with a calculus of phosphatic churacter.

The enlarged kidney presented three different forms of structure in separate portions of the organ. 1. One part presented a firm, whitish, almost homogenous appearance, with scarcely any visible vessels. 2. Another portion showed a structure much softer, of a brain-like appearance, and the white colour mixed with numerous red lines, like blood-vessels or enlarged capillaries filled with red blood. 3 . There were cavities filled with a red grumous mass of broken up structure without organisation, arising from the destructive process which had been fully developed in those parts, with, at the same time, considerable effusion of blood.

REMarks. The different states in which the organ was found, in this case, might suggest the idea of a process of softening analogous to that which takes place in tuberculous deposit, but a moment's reflection will show the analogy to be false. Cancer being an organised structure-consisting of cells, either capable of increasing by means of one cell throwing out others, cystoblasts (Walshe), or continually deposited by the vessels which bring them, as it were, to the cancerous depot Iebert) - cannot be amenable to the same laws which govern deposits incapable of organisation. Lebert
(Traitê Pratique des Maladies Cancéreuses) contends with great reason that softening in cancer is not a phase of its development, but one of the various effects of deranged nutrition, which may, or may not happen.

Another effect of this deranged nutrition acting upon the blood vessels, according to Lebert, is the effusion of blood in the substance of the morbid tissue. This appears to have taken place in the case under consideration, and hence an explanation of the cavities and their contents. The absence of pulsation in the left radial artery was not accounted for by the dissection; had a more minute investigation been instituted, in all probability some secondary deposit would have been found, which, by its relative position, might have explained this effect. The renal hæinorrhage was possibly due, in some degree, to the calculus in the right kidney, as well as to the cancerous disease in the left.

Cheltenhan, January 6th, 1sit.

\section{A CASE OF CONGENITAL DEFICIENCY OF THE LACHRYMAL SECRETION.}

By JAIIES VOSE SOLOMON, Esq., Surgeon of the Birmingham and Midland Counties Eye Infirmary.

THE function of the lachrymal gland is sometimes so active, irrespective of emotional excitement, that a greater quantity of tears is secreted than can be carried off by the derivative passages, constituting the well known symptom termed "epiphora".

On the other hand, it is, in a few rare instances, so passive, that the power of shedding tears is suspended, or

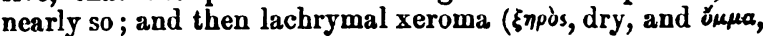
eye) is, in the technical language of ophthalmology, said to be present; not that the eye appears dry to an observer, but it feels so to the patient.*

This phenomenon has been hitherto described in ophthalmic works, either as a symptomatic, or as a sympathetic affection only. In the following case, it seems to be idiopathic, and hence its interest to the profession.

Cuse. A strong healthy boy, 22 months old, the offspring of healthy parents, was brought to me at the Birmingham Lye Infirmary in May 1853, in consequence of having two small opacities upon his right cornea.

The mother stated, upon one of his risits, that he had never shed tears but once, and that was after he had been left in a room by himself for an hour, when two drops were observed upon his chcek.

I made the following notes:-The eyeballs are prominent, and subject to a slightly rotatory motion, which is only noticeable upon minute examination; there is no opacity of the lens, or of its capsule, to account for this oscillation. The natural movements of the two globes are consentaneous. There are no indications of amaurosis. The irides are blue; their apertures contract when suddenly exposed to light. The conjunctiva and derivative passages lined by it are normal. The surface of the eyeballs is bright and shiny. In fine, with the exception of the corneal opacities, the structures of the eyes are quite healthy. Digital examination detects no anormalty in the lachrymal gland. The opacities are referred to an ophthalmia that affected the child when two months of age; since then, he has had catarrhal conjunctivitis. No relative of the patient has been affected with a similar lachrymal peculiarity.

The question naturally suggested by the narrative was, whether any tears were secreted? Were the two drops, once observed to bedew the cheek, merely serous exudation from a highly conrested conjunctiva? With a view to determine this point, and to aid the absorption of the

* If it were not that a change of nomenclature ulways eutrils a degree of incourenieuce, I should be iuduced to surgest tho ubuidomuent of the term jachrymal xeroma, as conresiug an erroueous idtil of the actual state of the ocular surfuce, and the substitution of lachryual acrinia-a priv., kpivw, to separate-a paucity or non-secretion of tears. Aud I would limit the word xervins to that diseased cinditivn of the conjunctiva which is attended by loss of the characteristics of mucotis membrims 
pects on the cornen I introduced s diluted preparation of the ointment of red oxide of mercury within the ejelids; the child cried lustily, and the stimulated eje was rendered perhaps a little more moist, but no tears flowed upon the fids, or collected at the inner angle. This treatment was repeated on several occasions, and always with the same results, even when the tip of my finger was placed over the orifices of the lachrymal puncts, so as, if possible, to obstruct them.

On the 1st of July, little change having taken place in the opacities, about which the mother of the patient expressed much solicitude, a stronger stimulus (tinctura opii) was applied to the right conjunctiva, which then became red, and a clear colourless fluid of saltish taste gushed from the eye, and rolled upon the cheek; but although the child screamed with pain, its left eye and lachrymal gland preserved throughout a perfectly quiescent condition. About a week afterwards, the tinctura opii was applied to the latter, and it wept, its fellow being at the same time tearless. This treatment proved satisfactorily the presence of two lachrymal glands, and their ability to secrete tears under an extraordinary stimulation only.

The cause of their torpidity appears to me, at the present age of the patient, to be inexplicable. I believe this to be the first case recorded in which such an affection, uncomplicated by disease of the conjunctiva, has been congenital. The more common causes of a suppressed, or diminished secretion of tears, are-disease of the lachrymal gland; certain cases of amaurosis; the impaired nutrition of advanced life; violent grief; and closure of the lachrymal ducts.

Before concluding this communication, I must notice that Mr. Wardrop has related in the Lancet for Nor. 29th, 1853, a case of congenital dryness of the conjunctiva (xeroma), with insbility to weep, in consequence of the intimate adhesions of the eyelids to the globes obstructing the lachrymal ducts.

A similar condition is occasionally produced by chronic inflammation of the conjunctiva in the adult. Indeed, it is possible that Mr. Wardrop's case may have been the result of intra-uterine conjunctivitis.

Birmingham, January, 1854.

\section{A CASE OF DISLOCATION OF THE HEAD OF THE HUMERUS UPON THE DORSUM OF THE SCAPULA.}

By ROBERT DUNN, F.R.C.S., etc.

Mr. W IEst's case of dislocation of the os humeri upon the dorsum of the scapula, in the Association Joursal for Jan. 6th, is highly interesting, not merely on account of its rarity, but from the detail of how the accident occurred. Few such cases are to be found in the annals of British surgery. The very possibifity of their occurrence has been denied by so great a surgeon as Boyer. It has reminded me of an instance which came under my own observation many years ago; and I need offer no apology for placing it upon record. I communicated the particulars at the time to my much respected friend, the late Mr. Bransby $B$. Cooper, and he was regularly in the habit of relating the case to his class, in his surgical lectures at Guy's Hospital.

The case was that of an old woman, aged 60 years, living in Hen and Chicken Court, Fleet Street, who had fallen down in a fit, and to whom I had been called. Before I arrived, she bad recovered from the fit, but she complained to me of great pain in the shoulder, and of inability to move the arm. Upon a careful examination, which I was induced to make, from the appearance being 80 very different from what might have been expected from paralysis, or any other neuralgic affection, I soon perceived that the articulatory surface of the humerus had been thrown from the glenoid cavity of the scapula. Upon viewing the two shoulders, for the purpose of discovering the deviation from aymetry, it gave an appearance on the affected side as if the glenoid cavity had been thrown forwards, and rendered, particularly preminent. The whole arm appeared shartar? particularily pred forterds, but separated from the body; the head of the bone could be distinctly felt upon the dorsum of the scapula, producing a considerable tumour, and forming the grand diagnostic mark of the nature of the injury. I raised the arm perpendicularly to the body, in the manner recommended for the reduction of such dis locations, but not being successful in returning the head of the bone into its place, and the attempt occasioning very considerable pain, I desisted, and proceeded in the following manner. The scapula being fixed, I made extension from the wrist in the direction of the displaced bone (without putting my foot on the axilla) for two or three minutes, while my friend Mr. J. Davison, surgeon, of Aln rick, then a pupil of Guy's, was directing the head of the bone forwards from the dorsum of the scapula, and in this way it readily slipped into its place.

Mr. Cooper attributed my want of success in reducing the dislocation in the way I at first attempted, to the want of strength on my part properly to raise the arm; and strongly recommends the perpendicular elevation, as the best mode in such cases for reducing the dislocated bone.

31, Norfolk Street, Jan. 9th, 1854.

\section{NOTES ON EPIDEMICAL DISEASES.} By WULIAM ADDISON, M.D., F.R.S.

$$
\text { ro. II. }
$$

INPLOENZA, CHOHERA, CONTIKUED FEVER, TYPHUS, $\triangle Q U E$, REMITTENT FEVER, DIAREHOA, DYBENTERY, BMAII-POZ, GCARIET FEVER, MEASLES, HOOPING-COUGH.

\section{BNDEMIC АTMOSPHERES.}

Exhanatroxs arising from marshes, the low shores of livers and harbours, from jungles, and other uncultivated and undrained places, constitute a poison which produces fevers of various types and degrees of intensity. There are situations in hot climates in which these exhalations generate a poison 80 intense, that a few inspirations of the air in which they are diffused is capable of producing death; and there are other situations in which a less highly concentrated poison accumulates, the inspiration of which for a short period produces a fever capable of destroying life in a few hours.

That substances mired or suspended in atmospheric air may be conveyed with it to the lungs, and immediately enter into the blood, any one may easily satisfy himself by passing through a recently painted room. The vapour of turpentine diffused through the room is transmitted to the lungs with the air which is breathed, and passing into the current of the cfrculation, will exhibit its effects in some of the fluid excretions of the body, even more rapidly than if it had been taken into the stomach.

Facts such as these help us to understand how disease may be produced and propagated through the medium of an infected atmosphere. Very striking effects from such a cause have been witnessed in the crews of ships. The health of the men has been perfectly good whilst at sea, but no sooner do they arrive in port than sickness, sometimes to a fearful extent, begins. On the other hand, sickness acquired in port diminishes, and fresh cases cesse to appear, on the ship again putting out to sea.

A fow years ago, the Centurion dropped her anchor in Bombay harbour, in the month of March, at which time the ship's company were in good health. A few days after, eighteen men were taken ill of fever in one night, and from that time, from eight to twelve men were daily added to the sick list, until the number amounted to 120 . In 1839 , fever of a very malignant kind appeared among the crew of the Vestal, then at anchor in Barbadoes. Fifty cases occurred in ten days; and there appearing but little prospect of the disease abating whilst the ship remained in port, she put to ses. On the fourth day after the divease 